\title{
The effects of ursodeoxycholic acid in the management of sepsis-induced cholestasis in rodents
}

\section{Randa H. Ainosah}

East Jeddah Hospital, Ministry of Health, Saudi Arabia

\section{Magda M. Hagras}

Suez Canal University Faculty of Medicine

\section{Sameer Alharthi}

King Abdulaziz University, Faculty of Medicine, Department of Pharmacology

Omar I. Saadah ( $\square$ osaadah@kau.edu.sa )

https://orcid.org/0000-0002-3744-9907

\section{Research article}

Keywords: LPS-induced cholestasis; ursodeoxycholic acid; liver enzymes; apoptosis; cytokines and immunomodulatory activity

Posted Date: December 5th, 2019

DOI: https://doi.org/10.21203/rs.2.14471/v2

License: (9) (1) This work is licensed under a Creative Commons Attribution 4.0 International License. Read Full License 
The authors have withdrawn this preprint from Research Square 